\title{
Medical mobility and intersectionality across the United States-Mexico border
}

\section{La movilidad médica y la interseccionalidad en la frontera entre Estados Unidos y México}

Rosalynn Vega a* (i) https://orcid.org/0000-0003-4520-4114
Received on September 12, 2018. Accepted on October 25, 2018. Published on November 5, 2018.

${ }^{*}$ Corresponding Author: Rosalynn Vega, e-mail: rosalynn.vega@ gmail.com

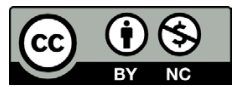

This work is licensed under a Creative Commons Attribution-NonCommercial 4.0 International License.
Texas, United States of America, e-mail: rosalynn.vega@gmail.com

\section{Abstract}

The objective of this article is to analyze how intersectional processes shape differing degrees of medical mobility (defined as facility of movement across national borders for the purposes of obtaining health care services or pharmaceuticals) across the U.S.-Mexico border for Spanish-speaking Hispanics and English-speaking Whites. Furthermore, this document explores how intersectional factors such as race, language, socioeconomic status, and citizenship shape medical mobility patterns. The research used ethnographic methods (in-depth interviews and participant observation) over a period of sixteen months (from May 2017 until September 2018) in Hidalgo County in the Rio Grande Valley of Texas. The results of the research are an ethnographic understanding of the limits of citizenship for both documented and undocumented health care seekers in the border region, and the circumstances under which different border residents turn to bioconsumerism. The article's conclusion makes a unique contribution to the literature by offering critical perspectives on relative privilege.

Keywords: intersectionality, racialization processes, medical mobility, citizenship.

\section{Resumen}

El objetivo de este artículo es analizar cómo los procesos interseccionales configuran diferentes grados de movilidad médica a través de la frontera de EE. UU. y México. Este artículo explora cómo factores interseccionales (la raza, el idioma, el estatus socioeconómico y la ciudadanía) moldean los patrones de movilidad médica. La investigación utilizó métodos etnográficos (entrevistas en profundidad y observación participante) durante un periodo de dieciséis meses (desde mayo de 2017 hasta septiembre de 2018) en el Condado de Hidalgo en el Valle del Río Grande de Texas. Los resultados de la investiga-

CITATION: Vega, R. (2018). Medical mobility and intersectionality across the United States-Mexico border [La movilidad médica y la interseccionalidad en la frontera entre Estados Unidos y México]. Estudios Fronterizos, 19, e016. doi:https://doi.org/10.21670/ ref.1816016 
ción son una comprensión etnográfica de los límites de la ciudadanía para los solicitantes de atención médica tanto documentados como no documentados en la región fronteriza, y las circunstancias en las que diferentes residentes de la frontera recurren al bioconsumerismo. La conclusión del artículo hace una contribución única a la literatura al ofrecer perspectivas críticas sobre el privilegio relativo.

Palabras clave: interseccionalidad, procesos de racialización, movilidad médica, ciudadanía.

\section{Introduction}

Isabella López is a Hispanic undergraduate student and dental assistant in the Rio Grande Valley, Texas. She strives to make ends meet to support her children and her younger siblings. On the weekends, she sometimes hand delivers items to her mother on the other side of the border in Reynosa. On one recent occasion, she accompanied her Spanish-speaking father to go get dental care in Progreso, Mexico. "Right when we crossed into Progreso, we were bombarded with dentists. Everyone is a dentist...There is a saying that it is easier to run over a dentist than a dog in Progreso" (Isabela López, 2017). The dentist told her father that he should get an enamel-colored filling because it will last longer than an alloy one. From her work experience, she knows that toothcolored fillings last approximately seven years while alloyed-colored fillings can be life-long if the patient flosses and brushes correctly. When she spoke up, she and her father were immediately surrounded by five dentists, all pressuring him to choose the enamel-colored filling. Meanwhile, Isabella was skeptical with regards to the education and training backgrounds of all of these purported dentists. "Everyone was calling everyone 'doctor,' 'doctor,' and I asked myself, 'Everyone here is a doctor?'” (Isabela López, 2017). The turnover of patients in the exam room was extremely quick, leading Isabella to feel concerned about the sterility of the instruments. Did they have time to clean the room or replace used instruments between patients? She watched to see if they would open a new sterilized pack of instruments, but before she could confirm, they were ushered out to make room for the next patient. Isabella acknowledged that the treatment was a lot cheaper - a porcelain crown in the U.S. costs about $\$ 1000$, but in Progreso the cost was $\$ 300$. She opines that the quality in the U.S. is better, and so the price difference is an appropriate reflection of quality. Even though Isabella knew that her father was being given inferior quality of care than if he had been seen by the dentist in the U.S., her family is uninsured and unable to afford U.S. dental care.

Dacia and Keane Danton are an elderly White couple that recently moved full-time to the Rio Grande Valley. As Winter Texans, they used to come down to South Texas from their home in Kansas during the harsh winter months and spend summers up North. However, this year, they decided their large home and 7 acres of land in Kansas required too much upkeep for their aging bodies. Where they lived in Kansas was the seventh most expensive county in the U.S.-thus, their transition to living fulltime in a mobile home in the poorest county in the U.S. was also a financial decision. Keane has arthritis, Barrett's esophagus, plantar fasciitis, and a "bad heart." He jokes about needing a psychiatrist after how he was "bled to death" financially for different tests to determine his eligibility for bariatric surgery. While he turned out not to be a candidate, he says that "They don't know how bionic I am.... I am very stubborn, and I 
think if you are going to be stubborn about something, you should be stubborn about positivity. You got to think positive" (Keane, 2017). Unable to pay to treat his plantar fasciitis in the U.S., he says, "I took out my pocket knife and took care of it. That would have cost me a few thousand dollars" (Keane, 2017). Keane sees the pedicurist in Progreso whenever he has an in-grown toenail-many of the services offered by the Mexican pedicurist would be under the purview of podiatry in the United States. Keane's wife, Dacia, has multiple expensive medications for her chronic health issues. While Medicare covered these medications for the first several months of the year, she "hit the donut hole" (Dacia, 2017) in May, and is now having to pay out of pocket. The price for these medications in Progreso is a little less than the co-pay at Sam's Club for the same medications. That is, once she has used up her Medicare benefit, it costs Diane between $\$ 600-700$ to fill her prescriptions for the rest of the year at a Mexican pharmacy.

This article explores how intersectional factors such as race, language, socioeconomic status, and citizenship shape medical mobility patterns. While others have published on medical migration (Roberts \& Scheper-Hughes, 2011; Thompson, 2011) and others on medical tourism (Connell, 2006), this article emphasizes the unique features of medical mobility. For the purposes of this study, medical mobility is defined as facility of movement across national borders for the purposes of obtaining health care services or pharmaceuticals. Furthermore, I consider not only the movement of people towards goods and services, but in the case of undocumented migrants to the United States, the movement of goods and services toward them.

Given the characteristics of the local population in the Texas Rio Grande Valley, this study analyzes and compares the experiences of the two most common demographic groups: Spanish-speaking Hispanics and English-speaking Whites. Many members of the latter group are "Winter Texans"-retirees from Northern states who spend winter months in South Texas where the weather is warm, cost of living is cheap, and, as this article demonstrates, dental care and pharmaceuticals are readily available on the other side of the border. The Rio Grande Valley is characterized by ongoing encounters between these two groups, extreme socioeconomic inequality, and close proximity to medical services in Mexico, making it the ideal location for the study.

In this article, I analyze how intersectional processes in the Rio Grande Valley shape medical mobility patterns across the U.S.-Mexico border for Spanish-speaking Hispanics and English-speaking Whites. These intersectional differences materialize in digital media (examples include print advertisements and social media), during border crossings, and decision-making processes regarding what medical services to seek and where to seek them. I explore the limits of citizenship for both documented and undocumented health care seekers in the border region and describe the circumstances under which different border residents turn to consumerism. In so doing, I will develop a critical perspective on relative privilege.

The rest of the article is structured as follows: In the next section, I describe the ethnographic methods through which qualitative data was collected for this study. Next, in the "Background" section, I provide contextual information that describes the demographical characteristics of the region where this research takes place. The third major section of this article is devoted to theoretical concepts. In it, I distinguish "medical mobility" from related terms such as "medical migration" and "medical tourism." I furthermore explain the benefits of merging the "theory of intersectionality" with "sites of racialization." I go on to contrast the concept of "citizen" with that of 
"bioconsumer". Detailed analysis of my ethnographic data appears in the fourth major section of this article. In this section, I include ethnographic vignettes from different stages of medical travel in order to illuminate differences between how Spanishspeaking Hispanics and English-speaking Whites experience and leverage their disparate medical mobilities. Furthermore, I address underground economies may be part and parcel with transborder communities of care. Finally, in the conclusion section, I return to the question of bioconsumption. The conclusion details how (in) accessibility of health care in the United States leads Spanish-speaking Hispanics and English-speaking Whites to seek medical care beyond the borders of the U.S. In essence, medical mobility is a sign post for the limits of citizenship. Finally, I argue that the intersectional analysis presented in this study, when applied to the concept of medical mobilities, provides fertile ground for future research on relative privilege.

\section{Methods}

This qualitative study relied on ethnographic methods: participant observation in clinic and community-based settings, in-depth interviews, and focus groups. Interviews were semi-structured and lasted from fifteen minutes to over an hour, with the average being approximately forty-five minutes. While each interview was tailored to the interviewee, my questions generally followed these themes: his or her experiences with medical care in the U.S.; motivating factors for medical mobility to Mexico; comparison of the two health systems; and decision-making processes regarding when, where, and how to seek health care services and pharmaceuticals. I also included questions to help me understand the interviewee(s) positionality in society (race/ethnicity, language spoken at home, socioeconomic status, education level, etc.), but I intentionally refrained from asking subjects about their citizenship or documentation status since doing so could cause anxiety and discomfort. By not over- structuring the interviews, I resisted scripting or leading the informants, allowing them to speak for themselves. Included in this study are 218 total subjects. Among these subjects are 29 physicians, 8 medical assistants and nurses, and 21 hospital staff and auxiliary service workers. The remainder are health care recipients and their families.

My data analysis is derived from detailed entries in my field diary, audio and video recordings from interviews, and digital ethnographic data gleaned from social media. Upon concluding my research, I engaged in an iterative process that used open coding to identify emergent themes and synthesize higher order constructs. All the names that appear throughout this ethnography are pseudonyms. This research has received Internal Review Board (IRB) approval.

\section{Background}

The research for this study occurred in Hidalgo County. According to the 2017 U.S. Census Bureau, all but $3 \%$ of the population was Hispanic or White. The tiny remainder was comprised of Black, American Indian, Asian, and individuals of two or more races. Of those who are White or Hispanic, 97.0\% identified themselves on census forms as 
"White alone," 92.2\% identified as "Hispanic or Latino," and 6.2\% identified as "White alone, not Hispanic or Latino" (United States Census Bureau, n.d.d). Stated differently, according to the Census Bureau's 2015 "ACs 1-year Estimate" data set, 768798 +/- N/A were Hispanic and $58583+/-459$ were White. The Census also states that $84.6 \%$ of persons age 5 years+ spoke a language other than English at home. Overwhelmingly, the other language that is spoken is Spanish-618 351 speakers in 2015. In this study, I use language to help distinguish between two comparison groups-that is, language served as a marker for separating "White alone, not Hispanic or Latino" from "White alone" (thus eliminating the overlap which leads to more than $100 \%$ according to U.S. Census categories) (United States Census Bureau, n.d.a).

The median value of owner-occupied housing units was $\$ 81400$ and the median gross rent was $\$ 677$. These figures are indicative of the inexpensive cost of living when compared to the United States at large, but what these housing costs mean for local families can be better understood in context. Small Area Health Insurance Estimates for 2015 indicate that $31.2 \%$ of persons were living in poverty. The median household income is $\$ 36094$ per year, and the per capita income was $\$ 15240$. In this article, I point to the close relationship between race and socioeconomic status. My argument is bolstered by Census figures showing that Hispanics are the largest race living in poverty (255 $241+/-17931)$.

With regards to health, the region was highlighted in an article by Atul Gawande in the New Yorker due to the local "cost conundrum" (Gawande, 2009). That is, while the population reflects a high percentage of poverty, health care spending is extremely high. According to the Small Area Health Insurance Estimates (SAHIE) for 2015, 32\% of the population is uninsured (Bowers, Gann \& Elser, 2017). Despite the high percentage of poverty and uninsured individuals, the total health care and social assistance receipts/revenue in 2012 according to Census estimates was \$3 479014 000. According to The Dartmouth Atlas of Health Care (2014), \$12 336 in Medicare reimbursements were issued per enrollee.

In 2016, 27.9\% of the population was foreign born persons (United States Census Bureau, n.d.c). The "ACs 1-year Estimate" reveals that in 2014, 79.6\% of the population were citizens, while the figure was $79.7 \%$ in 2015 (United States Census Bureau, n.d.b). The Migration Policy Institute in Washington D.C. estimates that 100 000 undocumented people reside in Hidalgo County. The median native-born age is $21.1+/-0.4$ years while the median foreign-born age is $44.9+/-1.1$ years (the median age overall is 29.1). The population is less educated than the United States averageonly $17.4 \%$ of persons age 25 years+ possess a bachelor's degree. However, when the Migration Policy Institute used ACs data to consider the undocumented population alone, they determined that about $67 \%$ don't have a high school diploma, and only $6 \%$ have a college degree (Migration Policy Institute, n.d.).

\section{Theoretical Concepts}

In this section, I will discuss the theoretical concepts that orient this work. First, I discuss how "medical migration" and "medical tourism" have been researched by medical anthropologists. In doing so, I will explain why I have instead chosen to use the terminology of "medical mobility" in this text. Second, I will describe the theory 
of "intersectionality," and how I merge this theory with that of "sites of racialization" in order to make an argument for "intersectional racialization processes." Lastly, I will elucidate the meanings of "bioconsumer", specifically in contrast to the concept of "citizen." Together, these concepts will be put to work in the analysis section of this article, thus distinguishing nuances between the experiences of Spanish-speaking Hispanics and English-speaking Whites in the U.S.-Mexico border region.

\section{Medical Migration vs. Medical Mobility}

Medical migration has emerged as a vibrant topic of ethnographic inquiry within medical anthropology. Many of these studies analyze how medical therapies are reshaped and modified when both the therapies and health care seekers travel across geographic and political economic terrains (Roberts \& Scheper-Hughes, 2011). Ethnographic observations bolster Thompson's claim that "medical migrations are increasingly part of the very fabric of the transnational world order" (Thompson, 2011, p. 205), pointing to the transnational nature of health care in the contemporary world. That is, ethnographic studies on organ transplantation, in-vitro fertilization, and elective cosmetic surgeries demonstrate the multitude of ways in which medical migrants seek health care services and resources outside the country in which they reside. Others, highlighting the socioeconomic gap between those who seek health care services and the geographic contexts in which services are rendered have instead referred to "medical tourism." This latter phrase diagnosis structural inequality since medical tourists tend to be members of the global elite (Connell, 2006).

In this study, I have chosen to focus on "medical mobility" instead of "medical migration. "The word "migration" connotes a certain degree of permanence in the place to which migration occurs. In contrast, the trips across the U.S.-Mexico border described in this study are brief-those who travel across the border return very shortly to their place of residence (usually within hours), and those who are recipients of transborder care request these services on an occasional basis. My focus on "medical mobility" casts a light on differing degrees of facility of movement, thus bringing into stark relief the contrasting medical practices on the park of mobile, documented residents versus undocumented counterparts who cannot cross the border without high risk of no return. This research in medical mobility adds complexity to existing research on medical migration by signaling how multiple axes of inequity shape the movement of people and resources across national borders. Specifically, this research explores how differing levels of vulnerability influence how U.S. citizens versus U.S. residents of Mexican origin leverage divergent medical mobilities to access health care. It furthermore resists some of the assumptions made when using the term "medical tourism" since the experience of medical mobility can be devoid of affluence. While in medical tourism can often incorporate leisure and luxury, medical mobility is more often motivated by need given insufficient access to health care in one's country of residence. 


\section{Intersectional Racialization Processes: Merging Intersectionality with Sites of Racialization}

In this article I compare two different groups: Spanish-speaking Hispanics on the one hand and English-speaking Whites on the other. As a whole, these groups are distinct on the bases of race, language, citizenship, and socioeconomic status, and related factors such as access to health insurance. In general terms, Spanish-speaking Hispanics are less likely to be U.S. citizens than English-speaking Whites. As a result, they often have less economic resources and decreased access to health insurance when compared to White residents of the Rio Grande Valley.

My argument draws from Kimberle Crenshaw's (2014) theorization of "intersectionality." I recruit the theory of intersectionality as a way for thinking about the problem of sameness and difference in relation to power and a foundational logic of interlocking oppressions (Cohen, 1997; Grzanka, 2014). Intersectionality is a conceptual tool for understanding how different dimensions of inequality coconstruct one another (Grzanka, 2014). Intersecting dimensions of inequality are not additive. Crenshaw's analogy of the increased likelihood for injury due to crossing traffic at an intersection elucidates how Black women sometimes experience gender discrimination in a similar way to White women, other times they experience racial discrimination similarly to Black men, and still other times they are discriminated against as Black women - not the sum of racism and sexism, but something that supersedes these individual categories and cannot be described as a derivative of White women's or Black men's lives. Crenshaw emphasizes gender discrimination against women who are already marginalized due to race and or class and argues that while racialized women face some of the same obstacles that more elite women face, they also encounter obstacles that are unique to them.

In this present article, I focus on "intersectional racialization processes": the merging of Crenshaw's theory of intersectionality with Khiara Bridges' perspective on "sites of racialization" (Bridges, 2011). Moving beyond notions of biological determinism, Bridges argues that race is a process. This study extends her understanding of processual race to medical mobilities. Like Bridges, I note how race and class are often "folded into" one another; however, I consider race to be the most valuable analytic along the U.S.-Mexico border.

In essence, by highlighting intersectional racialization processes, I am casting a spotlight on how differing degrees of medical mobility are structured by racial difference. I am combining these two theories in order to examine systemic domination that overlaps race, language, socioeconomic class, and citizenship, and is rendered visible through the distinct ways racialized bioconsumers ${ }^{1}$ engage with digital media, manage (im) mobility, plan medical mobility routes, seek particular services, and refer to "the other".

\footnotetext{
${ }^{1}$ For a more in-depth description of "bioconsumers" see Vega (2018). The concept will also be developed further throughout this present article.
} 


\section{Citizens vs. Bioconsumers}

Vega (2018) argues for the consideration of the bioconsumer (individuals for whom market-based consumption of medical services plays a formative role in how their identities are syncretically portrayed and perceived). According to this argument, the privileged do not position themselves as citizens through claims to public resources; instead, they accumulate cultural capital through privatized services. Thus, the main stakes of bioconsumption among the privileged are the presentation of self and accrual of cultural capital.

This current study aims to explore the applicability of the concept of bioconsumption and its ability to describe experiences of citizenship (or lack thereof) at the opposite end of the socioeconomic spectrum. The research unfolds in a geographic location largely characterized by poverty (Hidalgo County is routinely among the poorest counties in the United States), thus it is the ideal place to inquire about the utility of the concept of bioconsumption among the poor. I will argue that in this context, bioconsumption is not driven by the desire to accrue cultural capital and curate presentations of self. Instead, bioconsumption is a creative and resilient strategy developed by people living in situations of vulnerability due to overlapping causes of inaccessibility with respect to citizenship-based health care services.

\section{Analysis}

In this article, I will provide different "windows" into the divergent experiences of Spanish-speaking Hispanics and English-speaking Whites. Specifically, I have included ethnographic vignettes from different stages of travel (the planning stages before setting out; [im] mobilities and psychoemotional responses while crossing the border; engaging with people while "on the other side"; and, finally, how these differing engagements shape distinct understandings of "spaces" such that they produce different types of "places") in order to illuminate differences between how Spanishspeaking Hispanics and English-speaking Whites experience and leverage their disparate medical mobilities. While discussing how each of these two groups engage with medical service providers, I address underground economies and how certain illicit activities may, in fact, signal transborder communities of care.

\section{Before Setting Out: "Media-ted" Medical Mobilities to Mexico}

The decision-making processes of both Spanish-speaking Hispanic families and White Winter Texans are largely influenced and shaped by different forms of media that address their primary concerns. Thus, medical mobilities to Mexico are "media-ted" for both groups.

For Spanish-speaking Hispanics, the primary concern when considering medical mobility to Mexico is physical safety. They are all too familiar with the gruesome scenes of violence occurring across the border, since virtually all of the Spanish-speaking Hispanics I interviewed belong to families and social networks that span both sides of 
the border, leading to extensive experiences in the U.S. and Mexico. While I refrained from querying my informants about their individual documentation statuses, I was able to use focus groups to glean information about how both documented and undocumented individuals make decisions regarding medical mobility.

For documented residents of the United States, primary sources of information regarding the safety of medical mobility on any given day are telephone calls to family members living in Mexico and community alerts placed on social media such as Facebook. One young woman, Jade, told me that her father will call with updates. One day, he phoned and told Jade, "Tell your aunt not to come." Jade then joked with her father, calling him chismoso (a gossip). Defending the legitimacy of his concern, he said, "Métete en Facebook" ("log into Facebook") (Jade, 2018).

Formal media outlets in Mexico do not provide consistent, reliable information about gang-related violence as it is unfolding. Furthermore, the information that does emerge in Mexican media outlets is rarely relayed in U.S. media outlets. Spanish-speaking Hispanics are mobilizing through dedicated Facebook pages, thus creating a community-based, real-time alert system that defies national boundaries. The Facebook pages are updated by subscribers to the page, and posts include the specific gangs involved and the cross streets where the violence is occurring. As an example, Reynosa's alert page is called "Código Rojo Reynosa" (Code Red Reynosa). This information is then used by medical migrants to determine when it is safe to cross the border and to plan the most appropriate route.

Crossing the border safely requires a great deal of media-ted strategizing for documented U.S. residents; on the other hand, crossing the border is not an option for many undocumented counterparts. While the geographic distance between informants and family members living "on the other side" can be a mere five miles, the emotional distance is huge for informants who, due to their undocumented status in the U.S., are unable to enjoy the physical presence of spouses, parents, and children. They are barred from physically participating in medical mobility, since they may not be able to successfully cross back into the U.S. in the future. However, it is worth noting that undocumented Mexicans are sometimes able to access Mexican pharmaceuticals through documented members of their social network. Also, they take advantage of "under the counter" services—-dental procedures are one exampleoffered by Mexican-trained doctors making unlicensed house calls in the United States (see below). Both transborder pharmaceutical deliveries and dental house visits are arranged using digital means, usually via text and messenger.

For Winter Texans, fear regarding physical safety deters many from seeking cheaper health care alternatives in Mexico. For those who do cross, their decisions are also media-ted. Due to their older age; however, they do not use social media as a reference for strategizing. Instead, they are the targets of advertising. One elderly woman, Montana, showed me the English-language business card of her dentist, Ivon, in Progreso. As she handed me the card, Dawn (2017) commented on how curious it is that most of the space on Irma's business is dedicated to a picture of a White woman. Why had Irma not chosen the picture of someone with Hispanic features? "I would rather see a picture of her there," Dawn mused aloud. "It's as almost if she's saying, 'White people are welcome'". 


\section{(Im)mobilities and Crossing the Border}

The Spanish-speaking Hispanics and English-speaking Whites in my study expressed divergent feelings while physically crossing the border. When Winter Texans cross over the Rio Grande river into Mexico, they are immediately struck by the machine weaponcarrying military soldiers waiting at the end of the bridge. The visible reminder of potential violence causes most to feel uneasy, but not enough to turn around. The mild discomfort is quickly dispelled by the welcoming presence of health care providers and service workers in Progreso. For example, Keane (2017) explained, "They really take care of you down there.... I guess they like me. I like them. They are so gracious down there, they really are.... They work hard for their money, they really do." His fawning description of the waiters, pedicurists, dentists, and pharmacists he encounters may romanticize the quality of these encounters by omitting the intersectional inequalities upon which they are premised. What is missing from his description is an explicit link between intersectional racialization processes and the "gracious" behavior of workers who take care of him so well.

On the other hand, documented Hispanics confessed a sense of anxiety when waiting in line to cross back into the United States. What would happen if they lost their "papers"? A few years ago, before requirements for crossing the border were as strict as they are now, Isabella was primarily concerned with gang violence when planning her entrance into and exit from Mexico. She needed to deliver something to her mother, who lives just a few blocks away from the border on the other side. If she were to drive, she would have to drive deeper into Reynosa due to the intricate web of one-way streets. Instead, she decided to walk to her mother's house, carrying the objects for delivery in her hands. When she returned to the border for re-entry into the United States, however, she realized that she forgot to bring her driver's license with her because she decided not to drive. The immigration officer told her that without official identification, she would not be allowed entrance into the United States. Isabella panicked, thinking about her children on the other side, and what would happen if she were not allowed to return to them. She started to cry and pleaded with the immigration officer to let her enter. She finally convinced him by giving him information about the dental office where she is employed.

Isabella's feelings of despair while attempting to migrate is unknowable for Englishspeaking whites. For White Winter Texans, entrance into Mexico is unconstrained by immigration laws. In fact, they never come in contact with a Mexican immigration officer. The greatest barrier to entrance is a turn-style, in which they must deposit 25 cents to walk through. Upon returning to the United States, their race protects them from experiencing the fear Isabella felt, since it is more likely that a U.S. immigration officer would admonish them for being forgetful before considering the possibility that they are illegal aliens. This race-based privilege is interpreted as brashness by some of my Spanish-speaking Hispanic subjects. For example, Valentina (2017) described the attitude of one White woman when crossing back into the United States sans identification: "We are white. What are they planning on doing with us? I'm white. I speak English. I'm American. Why wouldn't they let me cross?"

Using medical mobility as a lens, I argue that physical mobility across national borders - the degree to which individuals encounter obstacles or ease of movementcorrelates to social mobility (Vega, 2018). Stated differently, to be a "global citizen" is 
a privilege afforded to some, and a reality which excludes many. From this perspective, freedom of movement serves as a measure of social inequality. Those who possess greater physical mobility—and lack of fear when crossing borders-are more privileged within the transnational social order. Individuals' disparate experiences of border crossing is linked to documentation status, but it is furthermore determined by race, since even some documented Hispanics experience anxiety during border crossings. These ethnographic findings suggest that race is primary in defining social hierarchies in the U.S.-Mexico borderlands.

\section{Engaging with "the Other Side": Space and Place}

Over the course of my research, I noticed that while both Winter Texans and SpanishSpeaking Hispanics were concerned about violence occurring in Mexico, these groups behave very distinctly with regards to their engagements with physical space in Mexico. In so doing, their medical mobilities transform these spaces into different types of places. That is to say, the presence of medical migrants, or lack thereof, lends meaning to the physical space where it occurs, thus contributing significantly to the "sense of place" in that space (Urry, 2007).

Specifically, the medical mobilities of the Winter Texans I interviewed led them uniformly to the main strip of Progreso. Among White Americans, this small town has the reputation of being relatively safe when compared to larger cities in the region such as Reynosa and Matamoros. From the perspective of Mexicans living near Progreso, the strip is a sort of "playground" where White Americans go for cheap medical services, shopping, and margaritas. Due to the high volume of White medical migrants, the strip in Progreso is a place for medical tourism and other forms of consumerism (Baumann, 1993) discourse among White Americans contributes to the social production of the strip as this type of consumption-oriented place. For example, Keane (2017) commented to me that "After dark, it is completely different. There are ladies on the street." Smiling, he reflected that twenty years ago he would have fit in with the night life really well, but he has calmed down in his old age. Nowadays, Keane and Dacia take advantage of their medical mobilities to Progreso by visiting their favorite little restaurant where the waiters are so familiar with Dacia's preferences that they bring her tea before she even has a chance to ask.

The trustworthiness of particular pharmacies and dental offices is shared by word of mouth among seniors seeking advice about where to access medical services in Mexico. This information about where to go is coupled with admonishments about where not to go. Keane and Dacia go to "Paula's pharmacy" for their pharmaceutical purchases in Progreso due to friends' recommendations. Keane (2017) joked, "These people gripe about everything, so if they are happy, she has to be good". The pharmacy is located across the street from their dentist, and their pedicurist is next door to the dentist.

The "common knowledge" among the elderly White community regarding not straying from the main strip was reiterated by a border patrol agent when he visited a mobile park where many Winter Texans reside. He warned the residents not to go to Mexico-however, if they must go, stay on the street leading directly to the U.S.Mexico bridge, go no further than four blocks into Mexico, visit only in the early morning when crime is less likely, and travel in groups. Due to the generalized nature 
of this advice, the town of Progreso is a "non-place" for Winter Texans (Augé, 1995). That is, while the lives of many Progresans unfold throughout the town's multiple streets, these other spaces and the people living on them are completely unknown to Winter Texans, thus disappearing into diffuse perceptions of danger in their collective imaginary (Baumann, 1993).

Spanish-speaking Hispanics interact with space distinctly, thus producing different types of places on the other side of the border. In a focus group among Spanishspeaking Hispanics, eight participants referred to medically-motivated trips to Progreso, while twelve described medical trips to Reynosa. Three others shared experiences regarding trips to Matamoros and three more explained that their medical trips were to their family's place of origin in Mexico (away from the U.S.-Mexico border). While Reynosa and Matamoros are considered epicenters of gang violence, Spanish-speaking Hispanics navigated these spaces with greater specificity. In other words, they planned their routes based not only on real-time updates on the locations of gang violence (see above), but also incorporated knowledge regarding the relative safety of specific neighborhoods and the perceived likelihood of gang violence given past patterns.

\section{Underground Economies vs. Transborder Communities of Care}

While for Winter Texans Progreso is a place with one street extending four blocks, the places where the medical mobility of Spanish-speaking Hispanics occurs resembles a patchwork quilt, or a tree with main branches and multiple smaller branches. Furthermore, the directionality of medical mobility is not only of Spanish-speaking service seekers traveling to Mexico to access medicine and dental care at a cheaper price, but also includes service providers migrating in the opposite direction.

As mentioned above, some dentists trained and licensed to practice in Mexico make house calls to Spanish-speaking patients in the United States. They provide dental services through cash-based arrangements that allow the patients to avoid travel to Mexico and provide a profitable source of income for dentists. During focus groups, informants have also described transborder internal medicine services, including lab tests. In addition, some pharmacies arrange illicit delivery services-upon receiving text messages from Spanish-speaking Hispanics in the U.S., a pharmacy employee will walk the desired medication across the U.S.-Mexico bridge for hand delivery to customers waiting on the other side.

As a resident of Hidalgo County, I have personally traveled to Progreso, Matamoros, and Reynosa. On trips to Progreso, I have been asked by pescadores, "What are you looking for? Uppers? Downers? Sideways?" Furthermore, Dacia explained to me that during medical trips she has taken to Progreso with friends, she learned that many pharmacists are willing to mislabel the contents of pill bottles so that customers can surreptitiously cross illegal substances into the United States. Dacia prefers "Paula's Pharmacy" because she witnessed Paula's refusal to engage in this practice, even though the practice has become common among many other pharmacists. Through this experience, Paula earned Dacia's trust, and Dacia is confident that the medications that she buys from Paula are not counterfeit. During an in-depth interview, one informant described her participation in a network of organizations that seek to provide support for female undocumented migrants, many of whom have been the 
victims of rape during their migration trajectory. She explained that efforts to care for these women's health involve bringing over pharmaceuticals which can be used offlabel as abortifacients.

Thus, when Spanish-speaking Hispanic informants told me about the illicit delivery of services and pharmaceuticals from Mexico to the U.S., I initially took this to be part of a larger "underground economy" of illicit medical services unfolding at the U.S.Mexico border. However, in a focus group setting, informants were quick to correct me. They explained that these transborder services were intimately grounded in existing social networks. That is, when uninsured, undocumented individuals require dental services, lab tests, or pharmaceuticals, they reach out to their family members "on the other side." One informant explained to me that an old family friend, the neighbor of family members living in Mexico, is the dentist from whom attention is sought by undocumented family members living in Hidalgo County. Thus, while at first glance it may seem that dentists, internists, and pharmacists engage in illicit transborder provisioning of care primarily for individual profit, extended ethnographic inquiry reveals that these activities may also be motivated by a sense of commitment and service to the local community. Given that social networks extend into both the United States and Mexico, border communities develop creative responses for maintaining relationships of care despite a border wall that would seek to divide the border region into discrete nations.

\section{Conclusion}

In this conclusion, I return to the question of bioconsumption. I argue that the numerous forms of medical mobility described in this article speak to the stakes of bioconsumption in a context of multiple, overlapping vulnerabilities. That is, this intersectional analysis demonstrates how (in)accessibility of health care in the United States leads Spanish-speaking Hispanics and English-speaking Whites to seek medical care beyond the borders of the U.S.; thus, medical mobility is a sign post for the limits of citizenship. In turn, I argue that the differing ways in which these two groups exercise their medical mobilities provides fertile ground for future research on relative privilege.

\section{Medical Mobilities: The Stakes of Bioconsumption}

The English-speaking Whites in my study exclusively turned to medical mobility to fill in gaps in their health insurance. All of the whites in my study were insured, and they used their U.S.-based health plans for the majority of their health needs. The members of this group only used medical mobility to access dental care and medications. They did not use medical mobility for medical consultations, laboratory testing, diagnosis, or non-dental treatment. Often, when a particular medication was either not covered by their health insurance or required a copayment that is higher than the out-ofpocket price for the Mexican alternative, medical mobility became a viable option. Also, Winter Texans were more likely to seek dental services during transborder 
medical trips due to having less comprehensive dental insurance when compared to health insurance, perceptions of decreased risk for dental procedures when compared to internal medicine, and less willingness to pay for dental procedures when compared to non-dental procedures.

Dacia and Keane are clients of a dentist named Dr. Patela. His clientele is built by word of mouth. His office has about six exam rooms. During the winter months, his dental office has more patients due to the influx of Winter Texans needing dental care, so a hygienists perform dental cleanings. Keane and Dacia gave me this tip: if you visit during the summer, however, a dentist will do your cleaning. They described the installations as clean but not as modern as in Kansas-an acceptable situation for them since the prices are considerably cheaper. Recently, Keane needed sixteen new crowns. In Kansas, the dental work would have cost them \$1 000 per tooth. He joked, "I'm not worth $\$ 16000$." He reflected on the experience of having his dental work done for a fraction of the U.S. price and said, "That was real satisfying." Also, when he went back to the hygienist in Kansas, he got confirmation that he had made a savvy choice in seeing Dr. Patela for his crown replacements. The hygienist said, "the Mexican dentist did a real good job". Chuckling to himself, Keane smiled, "Now I got my Mexican teeth and I can eat anything now".

Spanish-speaking Hispanics, on the other hand, seek a wide variety of healthrelated services in Mexico. While their medical mobility habits also include purchasing pharmaceuticals and receiving dental services at a cheaper price, their medical mobility repertoire includes elective cosmetic procedures. I argue that the extreme socioeconomic inequality in the Rio Grande Valley places impoverished and affluent people in close proximity to each other, and these socioeconomic inequalities correlate to racial differences. The two groups in my study interact through what Urry (2007; referring to Augé, 1995) describes as "solitary contractuality": an arrangement in which people coexist or cohabit without living together. While this is immediately obvious in "non-places" like Progreso, it can also be more subtly observed in neighborhoods across Hidalgo County where de facto racial segregation exists and to which Spanishspeaking Hispanics visit only as housekeepers, gardeners, and repairmen.

The result of "solitary contractuality" is that those with fewer socioeconomic resources are acutely aware of the consumption practices of their more affluent counterparts. The exposure of Spanish-speaking Hispanics to affluent White consumption-paired with being "priced out" of the U.S. market—significantly drives medical mobility patterns for the Hispanics in my study. Through ethnographic research, I discovered that Spanish-speaking Hispanics turned to medical mobility for elective cosmetic procedures that they were exposed to in the U.S. but could not afford. These procedures include orthodontia and plastic surgery (especially of the nose, breasts, and buttocks). I argue that this medical mobility is entangled in Spanishspeaking Hispanics' aspirations for a better life, including a middle-class future for their children. For example, Gala is a Spanish-speaking housekeeper whose daughter is pursuing her bachelor's degree. Gala and her daughter work together while cleaning houses in a mostly White neighborhood. The earnings are used not only to pay for her daughter's education, but her braces as well. Braces in Reynosa, Mexico cost less than a third of the price compared to braces five miles away in McAllen, Texas. In focus group settings, 24 of 29 young adults either had personal experience or knew of someone who migrated to Mexico for orthodontia. For Gala and her daughter, orthodontia is an investment. While Gala herself is lower-class and lacks formal education, both braces 
and a college education may potentially open doors for her daughter, thus positioning her for a brighter future.

\section{Accessing Health: The Limits of Citizenship}

This work harks back to argument that individuals seek and obtain health care services through two modalities: that of citizen or that of consumer (Vega, 2018). The goal of the Affordable Care Act was to make health insurance affordable to all American citizens and legal residents. In part due to this Act, all of the English-speaking Whites in my study have health insurance. For elderly Winter Texans, many are beneficiaries of Medicare. Since Medicare or other forms of insurance are the primary means through which members of this group obtain health care services, they are primarily accessing health through the citizenship modality. When they encounter gaps in health insurance (for example, when Dacia "hit the donut hole" and was forced to pay for her medications out of pocket until reaching the "catastrophic" amount of out-ofpocket expenditures), they turn to medical mobility to nearby Mexico, thus switching to the consumer modality. As such, medical mobility is an indicator of the limits of citizenship for accessing health care in the United States.

The Spanish-speaking individuals in my study, however, were more likely to be uninsured or underinsured. For those without health insurance or who have insufficient health insurance, socioeconomic constraints or lack of legal status are often contributing factors. Some of these individuals qualify for Medicaid, and turn to medical mobility and the consumer modality when seeking services that are not covered by this federal program. Since Medicaid is less comprehensive than Medicare, the need to utilize the consumer modality may be more pressing. Undocumented counterparts are totally barred from accessing health care services through the citizen modality in the U.S. They are also unable to access health care services in their natal country of Mexico since leaving the U.S. represents a huge risk. Furthermore, while they would be eligible for a number of preventative services through Seguro Popular (Mexico's universal health insurance) on the bases of their citizenship, Seguro Popular does not cover less cost-effective treatments for chronic illness (Laurell, 2013).

In essence, medical mobility serves as a sign post for the limits of citizenship for both English-speaking Whites and Spanish-speaking Hispanics. Individuals turn to medical mobility when they are unable to obtain affordable health care through the citizenship modality. In so doing, they reposition themselves as consumers and access whatever health care services they are able to afford—sometimes risking physical safety in the process.

Vega (2018) how reproductive tourism became a status marker for women aiming to align themselves with the global elite. Within the context of that research, migrating for physical services and heightened physical mobility stimulated social mobilitytherefore, medical mobility was both desired and a privilege. In the case of medical mobility on the U.S.-Mexico border, however, a similar pattern produces greater nuance. Specifically, research on medical mobility across the U.S.-Mexico border highlights the distinction between those who engage in medical mobilities because they are able and those who turn to medical mobilities because they must. In other

words, while in former research I have observed how individuals position themselves 
primarily as consumers instead of citizens since foregoing public services in favor of privatized lifestyles includes them among the global elite, the present research signals how other individuals are have no other choice but obtain whatever they can through the consumer modality when the citizenship modality has already failed to meet their health needs.

\section{Relative Privilege}

These considerations lead me to consider the issue of privilege. While individuals with racial privilege enjoy greater physical mobility, their medical mobilities highlight gaps in health insurance, thus signaling need instead of marking affluence. For those without racial privilege, the degree of physical mobility is based on documentation status. Those with documents may be thrust into the consumer modality due to poverty and insufficient government support, thus signaling vulnerability instead of privilege; alternatively, they may pursue the consumer modality as a route for achieving the middle-class aspirations they could otherwise not afford in the United States. Those without documents are the most vulnerable of all-not only do they lack racial privilege, they also lack physical mobility, and are thus in many ways unable to position themselves as consumers or citizens.

The study of medical mobility across the U.S.-Mexico border affords valuable insights for a nuanced understanding of privilege. Privilege is not a binary category. That is, whether one is privileged or not in the social order is not a simple "yes" or "no" distinction. Intersectional racialization processes evince various degrees of privilege. For example, elderly Winter Texans who seek dental care and pharmaceuticals in Mexico due to gaps in their health insurance and the unaffordability of services and medications in the United States may not be considered privileged when compared to their more affluent peers. Furthermore, lower-class Hispanics who seek elective procedures in Mexico may be considered privileged by extended family members living in Mexico. Lower-class Hispanics who turn to medical mobility when they are ineligible for specific treatments through Medicare may be privileged when compared to undocumented individuals who are excluded from both citizen and consumer modalities. Therefore, medical mobility across the U.S.-Mexico border is a fertile topic for developing a more kaleidoscopic theory of privilege.

\section{References}

Augé, M. (1995). Non-Places: Introduction to an Anthropology of Supermodernity. London, United Kingdom: Verso.

Bauman, Z. (1993). Postmodern Ethics. Oxford, United Kingdom: Blackwell Publishers.

Bowers, L., Gann, C. \& Elser, S. (March 28, 2017). Library. Small Area Health Insurance Estimates: 2015 (Report number P30-01). Retrieved from https://www.census.gov/library/publications/2017/demo/p30-01.html

Bridges, K. (2011). Reproducing Race: An Ethnography of Pregnancy as a Site of Racialization. United States: University of California Press. 
Cohen, C. (1997). Punks, Bulldaggers, and Welfare Queens: The Radical Potential of Queer Politics. GLQ 3, 437-465.

Connell, J. (2006). Medical Tourism: Sea, sun, sand, and ... surgery. Tourism Management, 27(6), 1093-1100.

Crenshaw, K. (2014). The Structural and Political Dimensions of Intersectional Oppression. In P. R. Grzanka (Ed.), Intersectionality: A Foundations and Frontiers Reader (pp. 1621). Boulder, United States: Westview.

Gawande, A. (June 1, 2009). The Cost Conundrum. The New Yorker. Retrieved from https:// www.newyorker.com/magazine/2009/06/01/the-cost-conundrum

Grzanka, P. (2014). Intersectionality: A Foundations and Frontiers Reader. Boulder, Colorado, United States: Westview.

Laurell, A. C. (2013). Impacto del Seguro Popular en el sistema de salud. Buenos Aires, Argentina: Clacso.

Migration Policy Institute. (n.d.). Unauthorized Immigrant Population Profiles. Retrieved from https://www.migrationpolicy.org/programs/us-immigration-policy-program-data-hub/unauthorized-immigrant-population-profiles

Roberts, E. F. S. \& Scheper-Hughes, N. (2011). Introduction to Medical Migrations. Body \& Society, 17(2-3), 1-30.

TheDartmouthAtlas ofHealthCare.(2014).Retrievedfrom http://www.dartmouthatlas.org/data/ map.aspx ind $=225 \& \mathrm{ch}=191 \& \mathrm{tf}=36 \&$ loct $=3 \&$ extent $=-14071323.410590487 \% 20$ 2305693.8872850095\%20-7398676.589409513\%206806306.112714991

Thompson, C. (2011). Medical Migrations Afterword: Science as a Vacation? Body \& Society, 17(2-3), 205-213.

United States Census Bureau. (n.d.a). American Community Survey (ACS). 2015 ACs 1-year estimates. Retrieved from https://www.census.gov/programs-surveys/acs/technical-documentation/table-and-geography-changes/2015/1-year.html

United States Census Bureau. (n.d.b). American Community Survey: 2014 \& 2015 data [Data set]. Retrieved from https://www.census.gov/programs-surveys/acs/news/data-releases/2014/release.html

United States Census Bureau. (n.d.c). American Community Survey (ACS) 2016 ACS 1-year Estimates. Retrieved from https://www.census.gov/programs-surveys/acs/technical-documentation/table-and-geography-changes/2016/1-year.html

United States Census Bureau. (n.d.d). QuickFacts. Hidalgo County, Texas. Retrieved from https://www.census.gov/quickfacts/hidalgocountytexas

Urry, J. (2007). Mobilities. Cambridge, United Kingdom: Polity Press.

Vega, R. (2018). No Alternative: Childbirth, Citizenship, and Indigenous Culture in Mexico. Texas, United States: University of Texas Press.

\section{Interviews}

Dacia Danton. (October 5, 2017). Interviewer Rosalynn Vega.

Dawn. (November 16, 2017). Interviewer Rosalynn Vega.

Isabela López. (November 17, 2017). Interviewer Rosalynn Vega.

Jade. (March 1, 2018). Interviewer Rosalynn Vega. 
Keane Danton. (October 5, 2017). Interviewer Rosalynn Vega.

Valentina. (November 17, 2017). Interviewer Rosalynn Vega.

Rosalynn Vega

Medical anthropologist of binational U.S. and Mexican citizenship. She obtained her PhD in the Joint University of California, Berkeley-University of California, San Francisco (UCSF) Medical Anthropology Program and completed a Master's in Public Health with a concentration in Epidemiology at the uc-Berkeley School of Public Health. She is Assistant Professor of Medical Anthropology at the University of Texas Rio Grande Valley. Her research interests include: intersectionality, critical race theory, political economy, citizenship, and transnationalism in the U.S.-Mexico borderlands. Recent publications: Vega, R. (2017). Racial i(nter)dentification: The racialization of maternal health through the Oportunidades program and in government clinics. Salud Colectiva, 13(3), 489-505. 